\title{
Correspondence
}

\section{Epidural analgesia for labour and delivery: informed consent issues}

To the Editor:

We read the report by Pattee et al. ${ }^{1}$ concerning informed consent issues surrounding epidural analgesia for labour. They found that parturients, questioned after delivery, indicated a preference for full disclosure of potential adverse effects associated with epidural analgesia. They refer to full disclosure of all material risks as the acceptable legal standard for informed consent in Canada.

They did not consider the ethical principles of informed consent and disclosure in the setting of the labouring parturient requesting analgesia. The principles of medical ethics which should be considered include respect for autonomy, beneficence, and nonmalificence. ${ }^{2}$ Informed consent, fully respecting patient autonomy, may not be possible during labour. An autonomous decision should be amply informed, duly considered and deliberated, free of coercion, and consistent with known preferences. ${ }^{3}$ Respect for patient autonomy, while ideal in informed consent, may conflict with beneficence and non-malificence, if effective therapy is withheld unnecessarily.

While discussion of the implications and potential adverse effects of epidural analgesia early in pregnancy is an appropriate goal, this may not necessarily lead to an informed decision, as previous personal experience of the parturient with labour would serve as the only appropriate benchmark for comparison (impossible in the primiparous!).

While the results of their investigation are interesting, the reference to a legal standard of full disclosure as applicable to all patients rests on a narrow interpretation of the operative principles. Consideration of the ethical principles involved would suggest that a single standard of informed consent as applied to the labouring parturient may be impossible to achieve.

Dr. Andrew Clark

Dr. Michael Jacka

Department of Anaesthesia

Atlantic Health Sciences Corporation

Saint John, NB

\section{REFERENCES}

1 Pattee C, Ballantyne $M$, Milne B. Epidural analgesia for labour and delivery: informed Consent issues. Can J Anaesth 1997; 44: 918-23.
2 Beauchamp TL, Childress JF. Principles of Biomedical Ethics. 4th ed. Toronto: Oxford University Press, 1994: Chapter 1.

3 Loewy EH. Textbook of Medical Ethics. Toronto: Plenum Publishing Corporation. 1989: Chapter 2.

\section{Antibody levels of Helicobacter pylori after surgery}

To the Editor:

Helicobacter pylori ( $\mathrm{H}$. pylori) infection is a major cause of gastritis-associated diseases, and gastric or duodenal ulcers. ${ }^{1}$ In infected individuals, undergoing stress may aggravate this infection. We, therefore, examined whether serum IgG antibody levels of $\mathrm{H}$. pylori change after surgery.

Nine adult patients were studied. Three were undergoing abdominal surgery and six, neurosurgery. Venous blood was collected, before and after surgery, and also four weeks later. Serum IgG antibody levels were assayed by enzyme-linked immunosorbent assay against the high-molecular-weight cell-associated proteins of $\mathrm{H}$. pylori (Determiner H. pylori Antibody, ${ }^{\mathrm{TM}}$ Enteric Products Incorporated, USA). ${ }^{2}$ The serum levels were presented as,, $- \pm 1+, 2+$ and $3+$. Most patients documented no change of antibody levels after surgery (Table).

Although the IgG levels of $\mathrm{H}$. pylori seem to change slowly when the infection is initiated or aggravated, the level has been reported to increase immediately until eight weeks after inoculation of rhesus

TABLE Results of the serum IgG antibody levels of Helicobacterpylori

\begin{tabular}{llllll}
\hline $\begin{array}{l}\text { Patient } \\
\text { No. }\end{array}$ & Age & Sex & Surgical Procedure & \multicolumn{2}{c}{ Antibody Level } \\
\hline 1 & 21 & M & Distal Gastrectomy & - & 4 Weeks \\
\hline 2 & 59 & M & Distal Gastrectomy & $1+$ & - \\
3 & 77 & F & Distal Gastrectomy & $1+$ & \pm \\
4 & 68 & M & Cramotomy/Clipping & - & - \\
5 & 63 & F & Cramotomy/Clipping & - & - \\
6 & 75 & M & Craniotomy/Clipping & - & - \\
7 & 59 & M & Craniotonly/Clipping & $2+$ & $1+$ \\
8 & 55 & F & Craniotomy/aipping & $3+$ & $1+$ \\
9 & 75 & M & Craniotomy/ & $1+$ & $2+$ \\
& \multicolumn{5}{c}{ STA-MCA Anastomosis } \\
\hline
\end{tabular}

